\title{
Double endosonography-guided transgastric and transduodenal drainage of infected pancreatic-fluid collections using metallic stents
}

\author{
Joan B. Gornals ${ }^{1}$, Catalina Parra ${ }^{1}$, Nuria Peláez ${ }^{2}$, Lluis Secanella ${ }^{2}$ and Isabel Ornaque ${ }^{3}$
}

${ }^{1}$ Endoscopy Unit. Department of Digestive Diseases. Departments of ${ }^{2}$ Surgery and ${ }^{3}$ Anesthesiology. Hospital Universitari de Bellvitge-IDIBELL. Barcelona, Spain

\section{INTRODUCTION}

The use of self-expanding metallic stents (SEMSs) in draining PFC has been reported in small case series $(1,2)$. The practice of more than one transluminal drainage is rarely described $(3,4)$.

\section{CASE REPORT}

A 34-year-old male was referred to our hospital for drainage of symptomatic pancreatic fluid collections (PFCs) secondary to an acute pancreatitis. He was affected by gastro-duodenal and biliary obstruction. CT scan images revealed 1 perigastric pseudocyst (well-defined wall, without necrosis content, $70 \times 120 \mathrm{~mm}$ ) and 1 periduodenal walled-off pancreatic necrosis (WOPN) (thickened wall, partially liquefied collection containing solid content, 80 x $90 \mathrm{~mm}$ ).

Both PFC were accessed under endoscopic ultrasound (EUS)-guidance with a 6 Fr-cystotom and dilation tract using a $10 \mathrm{~mm}$ balloon (Fig. 1). First, the pseudocyst was drained transgastrically with a fully covered SEMS with bilateral anchor

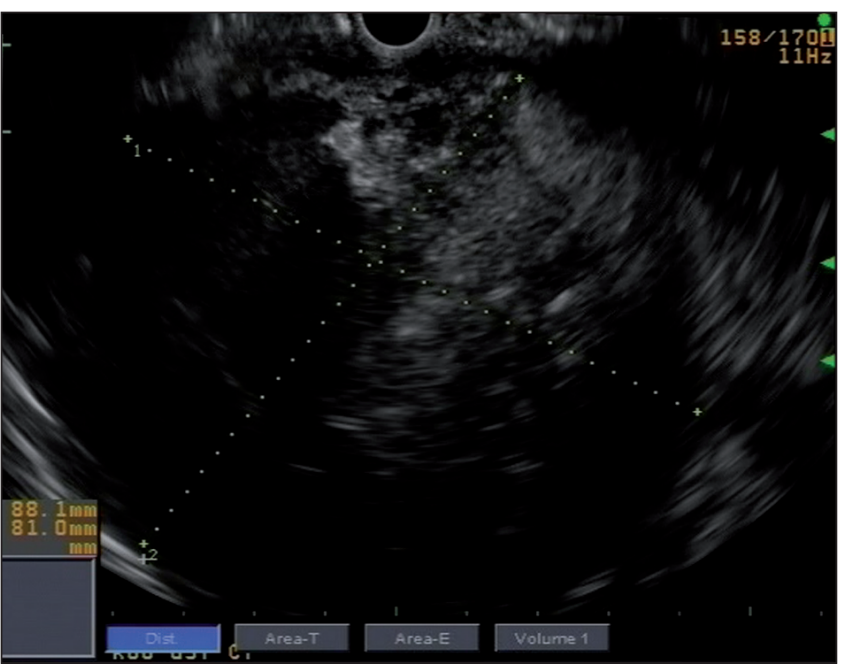

Fig. 1. EUS image of the walled-off pancreatic necrosis located in the end of the pancreas.

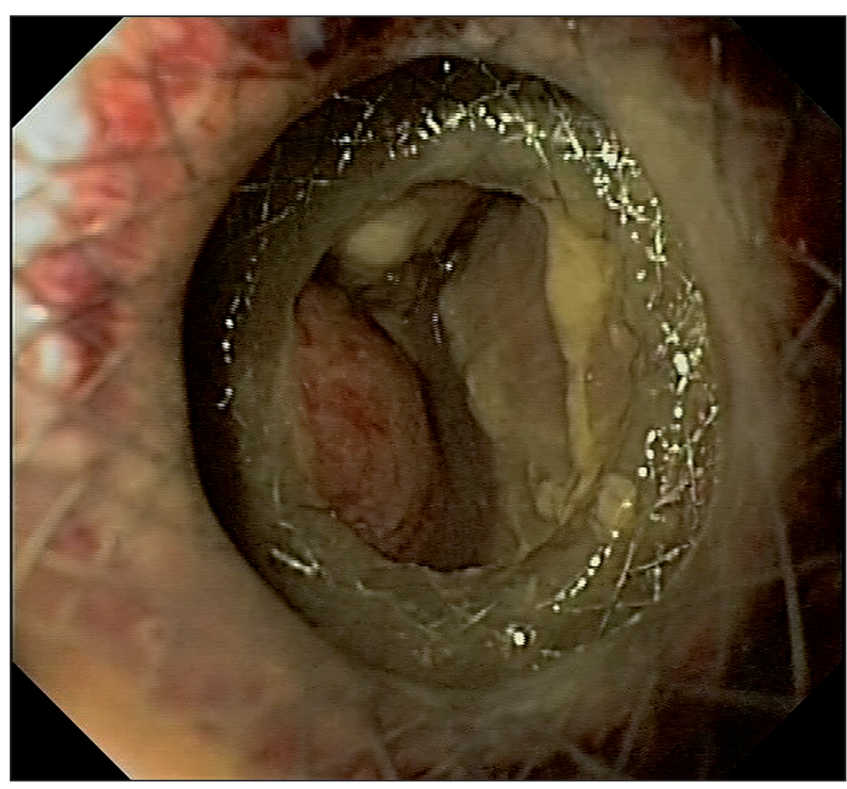

Fig. 2. Endoscopy view through the AXIOS stent showing a significant resolution of the lesion after the spontaneous drainaje of $800 \mathrm{ml}$ of turbid fluid. 

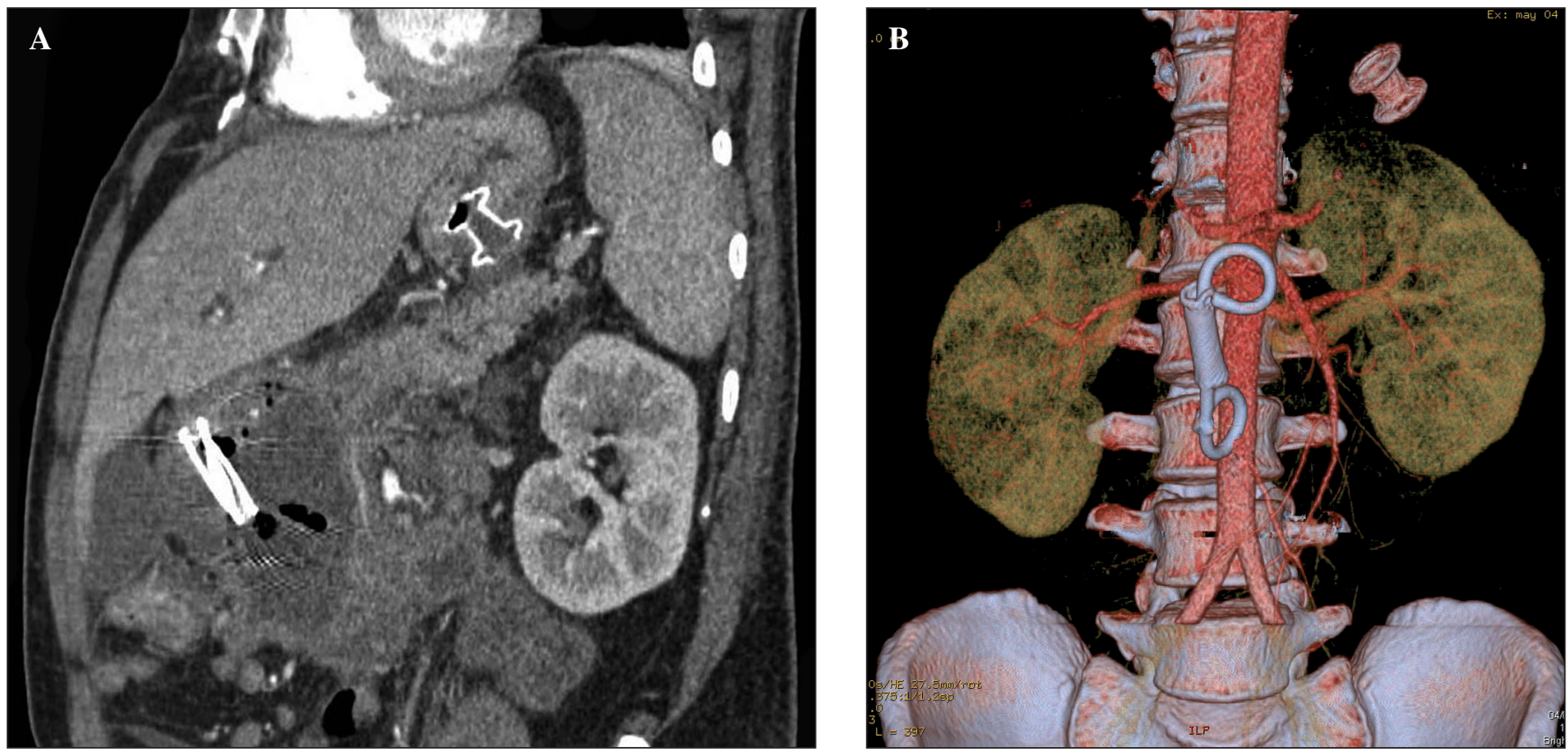

Fig. 3. CT scan coronal-sagittal oblique view (A) and 3-dimensional reconstruction (B) after the second drainage including both SEMS in the same plane: A cytogastrostomy (with a diabolo-shaped SEMS) and a cystoduodenostomy (with FCSEMS plus a coaxial plastic pigtail stent).
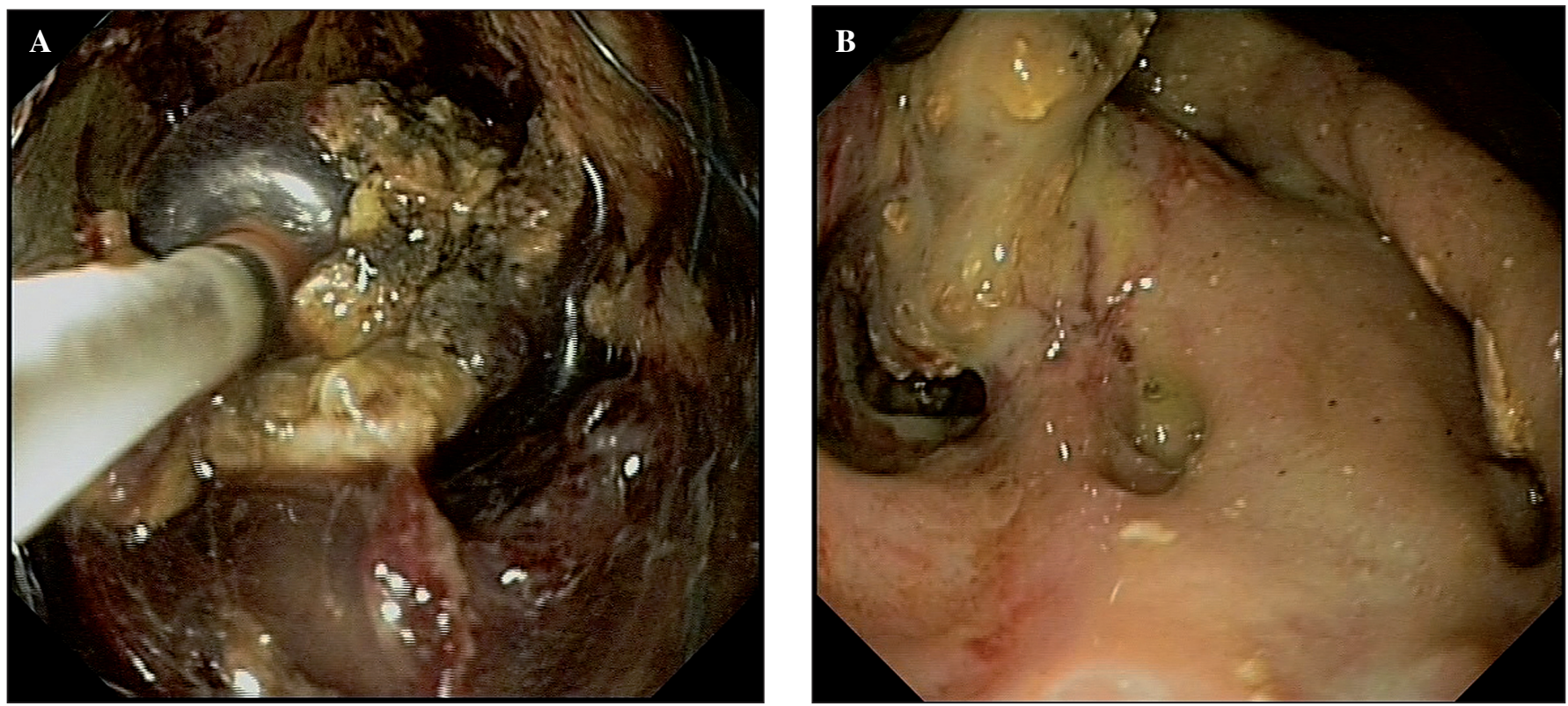

Fig. 4. Endoscopic necrosectomy of an infected walled-off pancreatic necrosis performed 6 days after a single transmural drainage (A). This maneuver allowed the extraction of non-adherent solid components of the infected cavity (B), improving patient symptons.

flanges (AXIOS ${ }^{\mathrm{TM}}, 10$ x $15 \mathrm{~mm}$; Xlumena, MountainView, CA) and $800 \mathrm{ml}$ of turbid fluid was aspirated (Fig. 2). Five days later, a WOPN was drained under EUS-guidance via transduodenal and a $10 \times 40 \mathrm{~mm}$ fully covered SEMS (WallFlex biliary Rx, Boston Scientific, Natick, MA) plus a coaxial 10 Fr x $5 \mathrm{~cm}$, double-pigtail stent to prevent migration were delivered and a purulent fluid was drained.
At day 6, abdominal pain and duodenal obstruction were persistent and a CT scan showed total resolution of the perigastric PFC and a decrease in size of the WOPN by $<30$ $\%$ with presence of necrotic contents (Fig. 3). An necrosectomy was performed delivering a new specific SEMS (Yo-Yo stent, 10 x $10 \mathrm{~mm}$, Niti-S; TaewoongMedical, Seoul, Korea) to keep open the duodenostomy (Fig. 4). 
Patient symptoms improved, with a significant resolution of the WOPN in a CT scan 15 days later. At 3 weeks followup, complete lesion resolution was revealed in CT scan images and all stents were removed.

\section{DISCUSSION}

The practice of more than one transmural drainage with SEMSs is effective for the treatment of infected PFC. The use of diabolo-shaped SEMSs improved the overall management.

\section{REFERENCES}

1. Talreja JP, Shami VM, Ku J, Morris TD, Ellen K, Kahaleh M. Transenteric drainage of pancreatic-fluid collections with fully covered self-expanding metallic stents (with video). Gastrointest Endosc 2008;68:1199-203.

2. Itoi T, Binmoeller KF, Shah J, Sofuni A, Itokawa F, Kurihara T, et al Clinical evaluation of a novel lumen-apposing metal stent for endosonography-guided pancreatic pseudocyst and gallbladder drainage (with videos). Gastrointest Endosc. 2012;75:870-6.

3. Mathew A, Gaffney RR, Moyer MT. EUS-guided double cystgastrostomy of two infected pseudocysts in series: A novel case of endoscopic cystocystgastrostomy. Gastrointest Endosc 2012;75:227.

4. Varadarajulu S, Phadnis MA, Christein, Wilcox CM. Multiple transluminal gateway technique for EUS-guided drainage of symptomatic walled-off pancreatic necrosis. Gastrointest Endosc 2011;74:74-80. 